\title{
AC 2012-4504: REVERSE ENGINEERING AS A LEARNING TOOL IN DESIGN PROCESS
}

Dr. Hamid Rad, Washington State University, Vancouver

Hamid Rad, Ph.D., is a faculty member in the Department of Mechanical Engineering at Washington State University, Vancouver. His areas of teaching and research interest include mechanical engineering design, design methodologies, and dynamic systems. His primary interest is teaching at undergraduate and graduate-level courses in the area of solid mechanics and design.

(C)American Society for Engineering Education, 2012 


\title{
Reverse Engineering as a Learning Tool in Design Process
}

\begin{abstract}
To include an element of practice in an engineering design course, a reverse engineering activity in the form of a project could enhance engineering students' learning experiences through the tear down of an existing product or device. This activity helps the student learn the principles behind the design of the product under study, uncover the inner workings of the device, as well as ways to redesign and improve the performance of the system.

In the body of this paper, a preliminary reverse-engineering design methodology is presented followed by case studies in which students as groups of three to four take an existing product and apply the reverse engineering technique to learn the design process behind the product. The types of product being studied are based on either instructor's suggested list of products or choice of the students design team. In most cases students selected a device with some kind of malfunction to study the reason behind the unit breakdown. These case studies are presented on reverse engineering projects performed by mechanical engineering students. Their learning experiences, as well as the challenges on trying to come up with conceptual ideas to improve the existing product based on their studies are presented.
\end{abstract}

The ABET outcomes for both students' and instructor's assessment presented in the paper prove that the reverse engineering process has been successful in our mechanical engineering program, enhancing students' skills in engineering design, hands-on experience, team-work, and engineering problem solving.

\section{Introduction}

Mech 314, Design Process is a three-credit Junior-level course offered in our Mechanical Engineering Department. The class meets twice per week for 75-minute sessions. The main focus of the course is on engineering design process. The textbook adopted for this course is Engineering Design by Rudolph J. Eggert [1], one of the best textbooks published in this area. This is a writing-in-the-major course, as such the students will have several major writing assignments in the form of design project reports. One of the topics introduced in the course is the concept of reverse engineering.

The practice of reverse engineering as a learning element in our design process course has been implemented for the past several years. The main objective of this exercise is to familiarize the students not only with the nature of redesign of a mechanical system, but also the ongoing process of investigating and understanding of the engineering principles behind the new products entering the market. In addition, as part of the assignment, student design teams working on various products must come up with at least one concept to improve the performance of the system being studied for their reverse engineering project.

Due to its very nature, reverse engineering is a common practice in diverse fields, such as mechanical design, electronics, software engineering, and consumer products in general. Among 
many valuable reasons for reverse engineering, we can refer to gaining competitive benchmarking methods to understand how a product functions, its material properties, manufacturing methods, and ways to improve the current design.

In literature, a number of authors have addressed the concept of reverse engineering as a learning and teaching tool. Jahan and Dusseau [2] use a portable water purification unit to introduce the concept to a freshman class of different engineering disciplines. Orta, P., et.al. [3] claim that reverse engineering is an invaluable tool to learn from the original structure and design, which is equivalent to going backwards through the development of the product. O'Brien and Abulencia [4] have implemented the reverse engineering principle for a sophomore fluid mechanics class. They have hypothesized that students improve their problem solving ability by dissecting problems in this manner.

Kellogg and Jenison [5] have utilized the process in an engineering design graphics course. Design teams of three to five had the task of disassembling a product given by their instructor to learn about design. McCracken and Newstetter [6] have used the reverse engineering methodology as a tool for design recovery for learning and teaching designing. Other authors have used this method primarily to teach how to design through hands-on design projects $[7,8]$. Otto and Wood [9] have started with customer needs, followed by reverse engineering, creating a functional model through teardown of a product.

This paper presents the results of the studies from a junior class on reverse engineering process as part of their assignment in the "Design Process" course. The main objective of this study, in addition to understand how the system functions, is to try to improve the existing design by at least one area.

\section{Objectives and Methodology}

Design of a new product usually starts with a forward design process in which the need is put forward by a customer/client. The students work in groups to solve challenging open-ended design problems. They come up comes up with several feasible alternative solutions from which the best solution is taken for further studies and analysis.

The reverse engineering process starts with tearing down an existing product to explore the physical principles behind it, to gather the technical data for documentation of the observations made by the researcher and the operation of a technology or components of a system. Since the design process course in our engineering school heavily emphasizes involving the students in hands-on learning activities, it helps them to understand the theoretical rationales behind the engineering design process. Our engineering students are introduced to the concepts of reverse engineering through a series of hands-on experiences of real-world products. Students in groups of three to four are given a list of basic products to choose from, or they may propose a product of their choice to disassemble for this study.

Through the teardown process of a product, the design team would learn how the product functions and how the parts or subassemblies interact with one-another. One of the main tasks is to have the students explore ways to improve the current product in at least one feature. 
Among many, some of the products in the list are vacuum cleaners, hand-held electric drills, coffee makers, RC cars, staplers, to name a few. Each may be selected by the students to practice on the reverse engineering process. Based on the past projects, in some cases a group of students select a system which no longer functions. They disassemble the product to investigate the cause of the malfunction. However, when the unit was reassembled, it started to work. The reverse engineering part of the design Process course offered here in our Mechanical Engineering Department proven successful and has increased the enthusiasm our engineering students to learn how the products are designed, manufactured, and assembled. This task seems to fulfill students' curiosity and provides valuable stimulus for students' learning as well as encouraging them to brainstorm new ideas to improve the current product.

\section{Case Studies}

In early part of the Design Process course offered at the junior level, after the forward engineering process is introduced, the topic of reverse engineering is covered. Students utilize the reverse engineering technique through hands-on experience with a selected mechanical system. They reverse engineer an existing product in form of design team. During the process, they investigate the working principles behind the unit, as well as, finding ways to improve the product through brainstorming. They present their studies in form of a technical report as part of the course requirement. In this paper some examples along with the outcomes of the types of projects our students worked on during the past several years, are introduced below.

\subsection{Lighted Ball-Point Pen}

In this project a group of students in the class of 2008-2009 [10] reverse engineered a lighted ball-point pen to better understand how it operates and to improve the function of its light emitting diode. The improvement consisted of modifying the switch that activates the LED to close and complete the circuit twice as often. Both a part and function decomposition chart were created and included in the document, as well as a part list and assembly drawing.

Before disassembling the pen, the students observed how the LED inside of the assembly functions; a switch is used to open and close the circuit when the user clicks the pen. However, the light did not turn on and off on every click. It only activated every four clicks.

After examining each part of the product, a product-component decomposition chart was created, as shown in Figure 1, which displays a hierarchy of the overall product, the subassemblies, and the specific parts. This was an important step to determine which subassembly contains the parts that accomplish the function of illuminating the LED. 


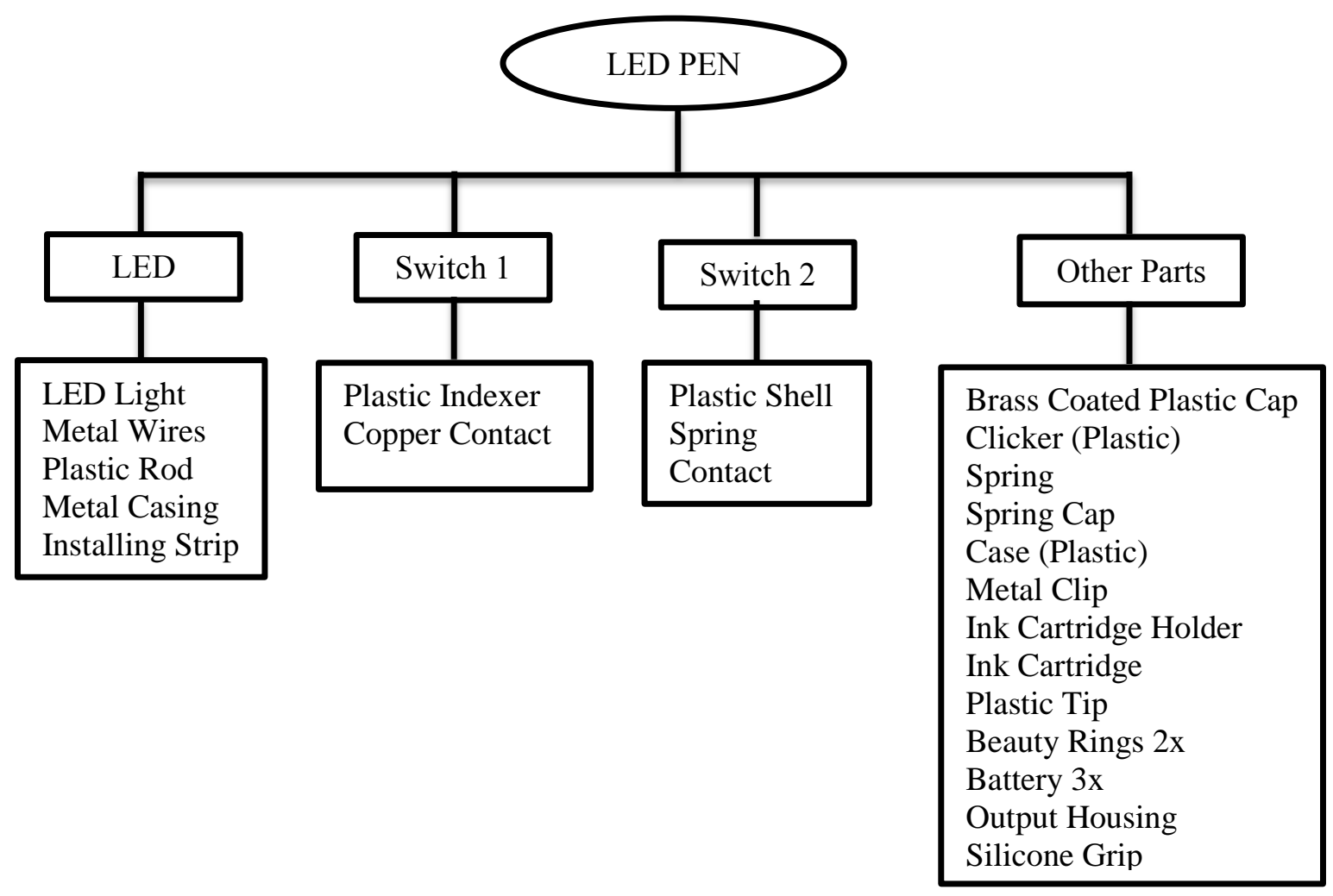

Figure 1 - Product-Component Decomposition Chart for Lighted Ball-Point Pen [10]

The product was disassembled for further study of how this deficiency could be corrected. A layout of the pen with different parts identified is shown in Figure 2.

Since the pen does not light up every other time it is clicked, the objective was to modify the switch so that it would do so. This was accomplished by adding a second strip of brass on the piece that rotates and closes the switch. 


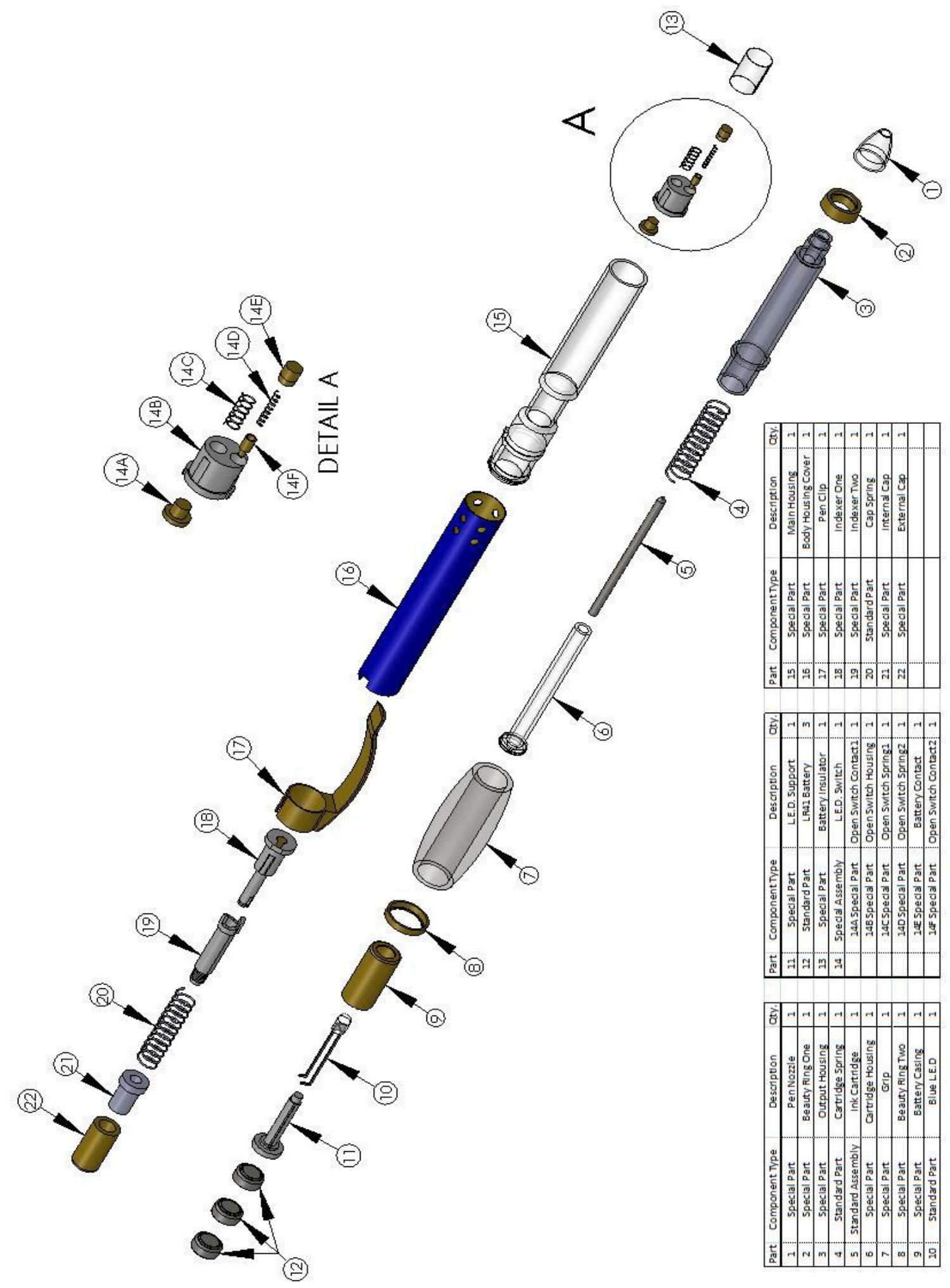

Figure 2 - Exploded View of Lighted Ball Point Pen with Bill of Materials [10]

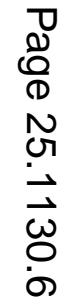


On its own, this strip only makes contact every four clicks shown in Figure 3(a). Adding an additional strip, shown in Figure 3(b), causes the LED pen to light up every other click. It is important that the pen does not light up on every click because one click is to open the pen and the other to close it.

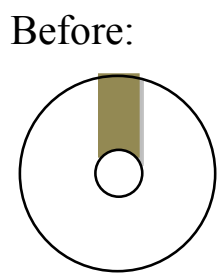

(a)

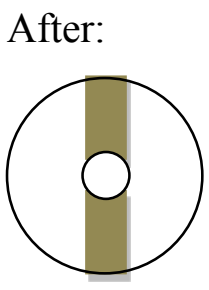

(b)

Figure 3 - Design improvement of the metal contacts (top view) for Lighted Ball Point Pen [10]

In conclusions while going through the reverse engineering process, the students working on this project learned about the different parts in the product, as well as how they functioned together as a whole. Ultimately, they came up with a way to improve the LED function of the pen, for the light being turn on and off on every other click, rather than every four clicks.

\subsection{Shop Vacuum}

Among several projects in the class of 2009-2010, a team of juniors in Design Process worked on reverse engineering a Shop $\mathrm{Vac}^{\odot}$ model 4025 [11]. There were several problems with this particular model that they had to address, including the high noise level during the operation, the life of the bearings on the motor, and the weight of the unit when full of water, which was too heavy for the average user. With these ideas for improvements, the team felt that the revised product was to be superior to the unit it replaced, and would be one of the best vacuums available in market.

To accomplish this task, the team produced and analyzed a customer survey based on 1000 customers to rate their experiences and gauge the important factors when using the unit. The outcome of this survey shows that most customers/end users emphasized that the Shop Vac ${ }^{(}$ must have sufficient power, perform well, and be safe. The team also employed a scientific and mathematical approach to solve the problems as follows.

The first design improvement was the noise level of the vacuum during the operation. The $80 \mathrm{db}$ TWA decibel rating approaches $85 \mathrm{db}$, the upper limit of tolerance. While not causing any major hearing loss, this level of mechanically produced aural output did cause several researchers to report significant "ringing" in ears after short periods of usage. It was concluded that further research should be conducted to determine if the loudness originates from airflow turbulence or motor noise. Theoretical research in acoustical harmonics might be utilized to superimpose noise canceling sonic wave forms generated by the interaction of the motor/tank/ducting system.

The second design aspect under consideration was durability due to bearing wear and the products' untimely demise. As the motor operates, it is cooled by the filtered exhaust from the 
debris storage tank. The fine unfiltered particulate that remains in the exhaust steam passes over the armature and lodges in the upper bearing faces. Over time this erosive effect causes the rotor and stator to contact, damaging the motor. To resolve this problem a Weighted Rating Table [1] was constructed, as shown in Table 1, for bearing upgrade. The idea was that a sealed bearing could still be economical and yet provide the service duration necessary to develop a reputation for a more robust product. As anticipated, the obvious solution was the sealed bearings with score of 6.75 to be a better solution.

Table 1 - Bearing Upgrade Considerations: Method of Weighted Rating [11]

\begin{tabular}{|c|c|c|c|c|c|}
\hline Design Criteria & Weight\% & Bearing As Is & $\begin{array}{c}\text { Weighted } \\
\text { Score }\end{array}$ & $\begin{array}{c}\text { Sealed } \\
\text { Bearing }\end{array}$ & $\begin{array}{c}\text { Weighted } \\
\text { Score }\end{array}$ \\
\hline Life Span & 0.3 & 3 & 0.9 & 8 & 2.4 \\
\hline Safety & 0.05 & 6 & 0.3 & 8 & 0.4 \\
\hline Weight & 0.05 & 8 & 0.4 & 7 & 0.35 \\
\hline Cost & 0.2 & 9 & 1.8 & 6 & 1.2 \\
\hline Performance & 0.1 & 6 & 0.6 & 4 & 0.4 \\
\hline Noise Level & 0.2 & 5 & 1 & 6 & 1.2 \\
\hline Maintenance & 0.1 & 4 & 0.4 & 8 & 0.8 \\
\hline Totals & 1 & 41 & $\mathbf{5 . 4}$ & 47 & $\mathbf{6 . 7 5}$ \\
\hline
\end{tabular}

Third, the large tank size should be reduced to a more manageable volume, preferably less than five gallons. This would bring the weight of the tank to a more manageable forty five pounds. In reducing the volume of the tank, the second moment of inertia would be moved closer to the ground if the tank became squatter with no corresponding loss in diameter.

In conclusion, the Shop $\mathrm{Vac}^{\odot}$ model 4025 is a highly popular product. The team has presented several ways to improve the product that would benefit the consumer, and the reputation of the company. It was decided by the design team, based on customer feedback, that the model 4025 vacuum should be improved.

\subsection{RC Car}

In this project an electric toy RC car was disassembled and analyzed. This task was accomplished by students in a team of four in the 2010-2011 class [12]. Its maneuvering capability, handling characteristics, aesthetics, range, and battery power were studied. The car was shown to be constructed inexpensively using injection molded thermoplastic with limited range and durability. In addition to testing for performance and parts cataloguing, three design alternatives were generated through group brainstorming and identifying various ways in which weak design points of the existing RC car might be improved. 
The RC car was dismantled to determine the original design concepts, manufacturing process, materials used, and to identify the parts within the product. The original design concepts for the $\mathrm{RC}$ car were standard A-arm steering, solid ABS plastic chassis, polystyrene body, solid rear axle, minimal circuits and wiring, two motors, and four standard AA batteries as a power source.

A detailed layout of the RC car and identified parts are shown in Figure 4.

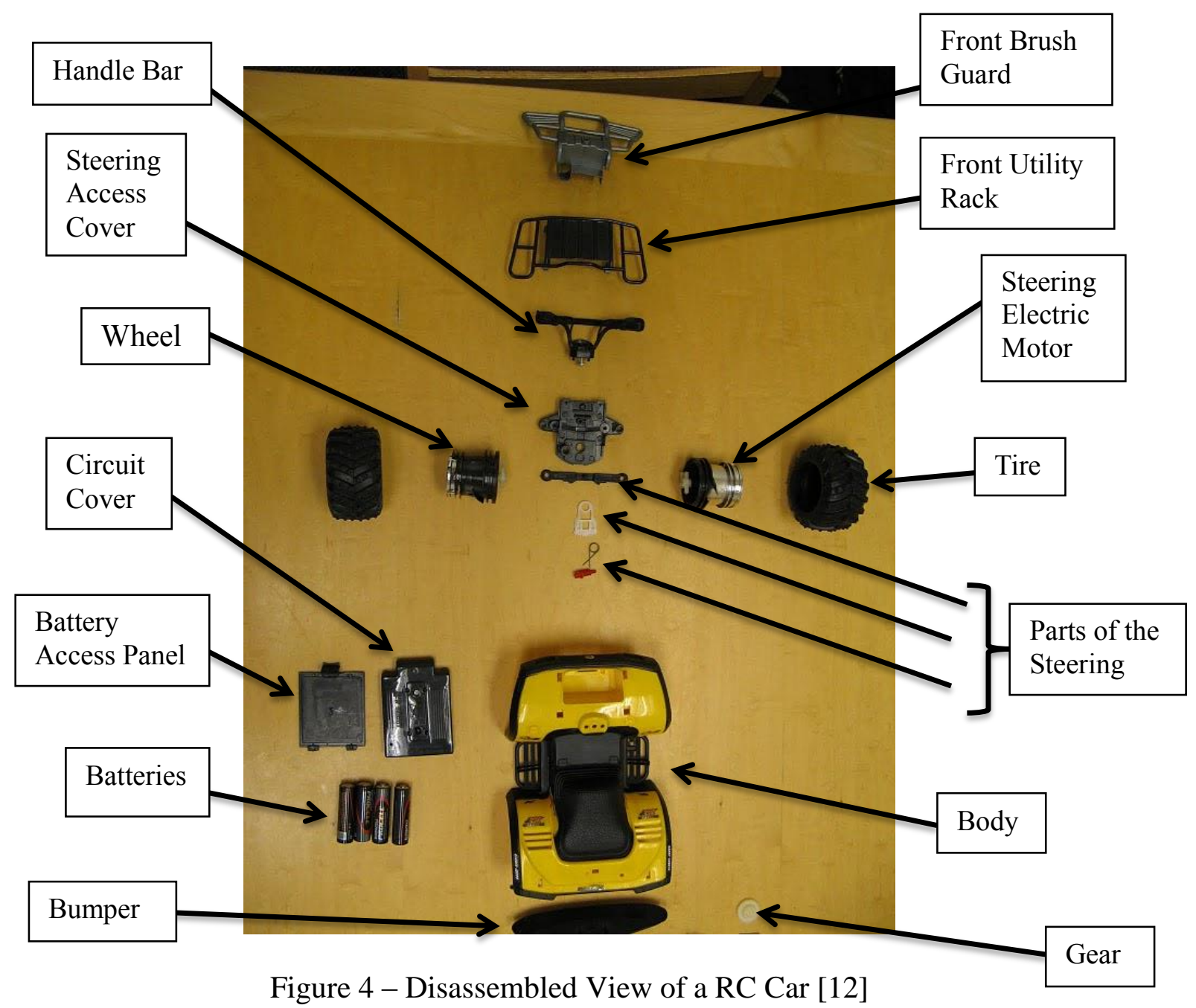

Injection molding was used as the production method for the chassis, the body, and some of the smaller parts. The design team used Fourier transform infrared spectroscopy (FTIR) [13] to analyze the molecular make-up of the chassis and the body. The chassis was determined to be made of $96 \%$ ABS plastic. The body was composed of a blend of ABS plastic and polystyrene.

From the engineering point, improvements to the current design could be weight reduction, suspension mechanism, increased battery life, and operating range, to reduce the overall cost. From the consumer points of view, the product must perform as intended, be reliable and durable. 
The concepts were evolved from the team members each coming up with two design ideas. The team synthesized the alternatives to come up with the best designs through brainstorming. The alternative concepts were entered into a Morphological Matrix [1] against system sub-functions to result in eighteen design alternatives as shown in Table 2.

Table 2 - Morphological Matrix for RC Car Alternative Designs [12]

\begin{tabular}{|c|l|l|l|l|}
\hline \multirow{4}{*}{} & \multicolumn{4}{|c|}{ Alternative Concepts } \\
\cline { 2 - 5 } & & \multicolumn{1}{|c|}{1} & \multicolumn{1}{c|}{2} & \multicolumn{1}{c|}{3} \\
\cline { 2 - 5 } & suspension & spring & gas shock & combination \\
\cline { 2 - 5 } & weight & $\begin{array}{l}\text { reduce } \\
\text { body/chassis }\end{array}$ & reduce size & \\
\cline { 2 - 5 } & & increase turn angle & $\begin{array}{l}\text { reduce wheel } \\
\text { base }\end{array}$ & split axle \\
\cline { 2 - 5 } & steering & larger receiver & & \\
\cline { 2 - 6 } & increase & & & \\
\hline
\end{tabular}

The eighteen alternative combinations from the Morphological Matrix were then reduced to just two designs by evaluating the cost constraints, engineering, and consumer requirements.

The study shows that these design modifications reduced weight on the chassis, introduced spring suspension, utilized a split axle that reduced turn radius, and a larger range receiver.

The second design alternative decreased the size of the RC car, which reduced material cost, used the split axle concept and a larger receiver. This design alternative was great for shipping, but increased manufacturing time because of the size of the parts.

In conclusion, the RC car is very well-designed with an optimal placement of motors for handling and tractive effort, sure to delight children with operations on carpet or wood surfaces. The injection-molded plastic construction is acceptable, as is the polystyrene body, and the dual motor design is very well handled, with electric transmission from batteries to motors being well-protected inside of the ABS plastic chassis/polystyrene body.

\section{Course Outcome Assessment}

The Design Process course has been offered for the past eight years. The concept of reverse engineering has been introduced each time and group projects have been assigned. Students in groups of three to four have worked on different projects of their own. The ABET course outcomes were assessed based on the following criteria:

A. Carrying out the design process, both forward and reverse, such as concept generation, modeling, evaluation, iteration, to satisfy project requirements.

B. Work within realistic constraints, such as economical, environmental, social, political, manufacturability, safety and ethical in realizing systems.

C. Applying engineering principles in analysis and design of mechanical components/ systems to meet desired needs. 
The students were assessed at the end of each semester through two different methods: students' surveys and instructor evaluations. Students were given a survey with the course outcomes as the questions and were asked to evaluate their level of achievement in scale of 1 (strongly disagree) to 5 (strongly agree). The results of above ABET outcomes are presented in Figures 5 through 7 . The additional elements of these assessments have been through project reports submitted by each design team and questions on the concepts of reverse engineering in exams.

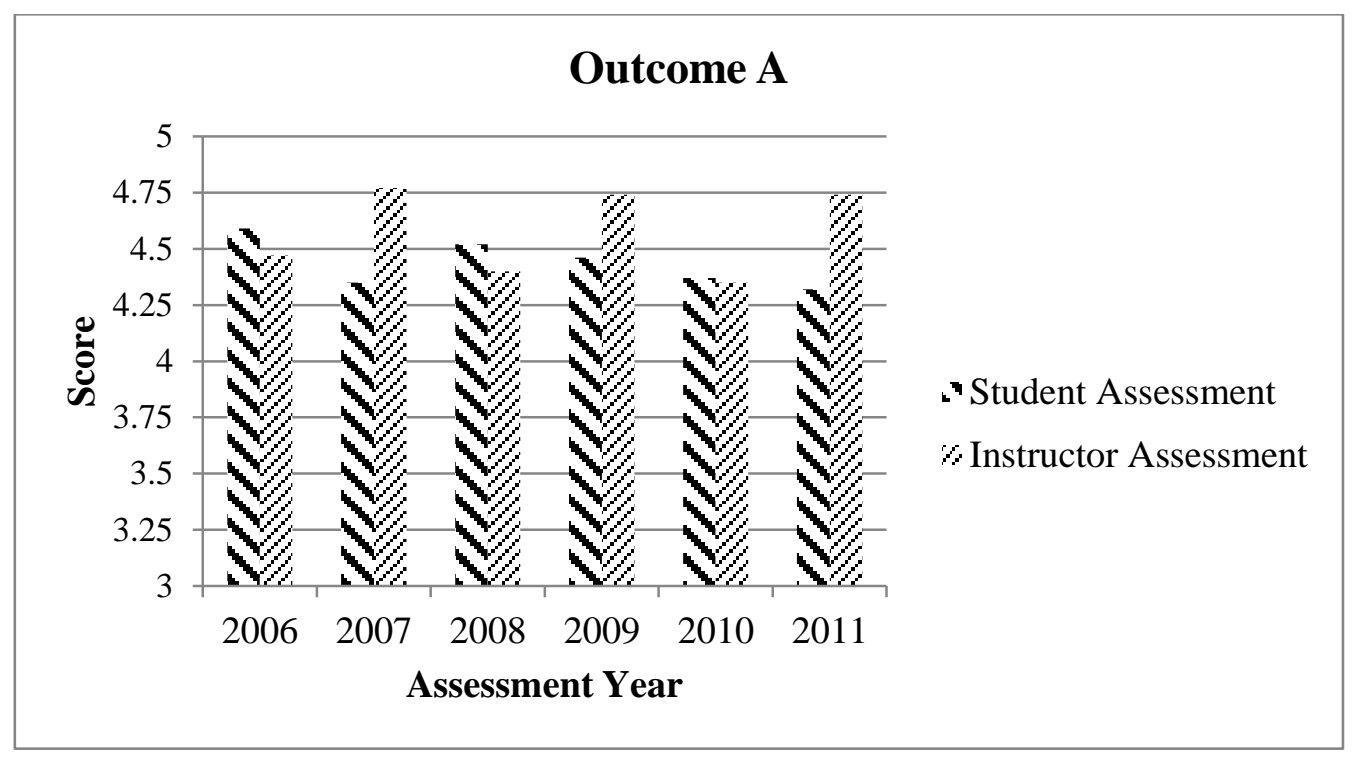

Figure 5 - Assessment of Students for ABET Outcome A

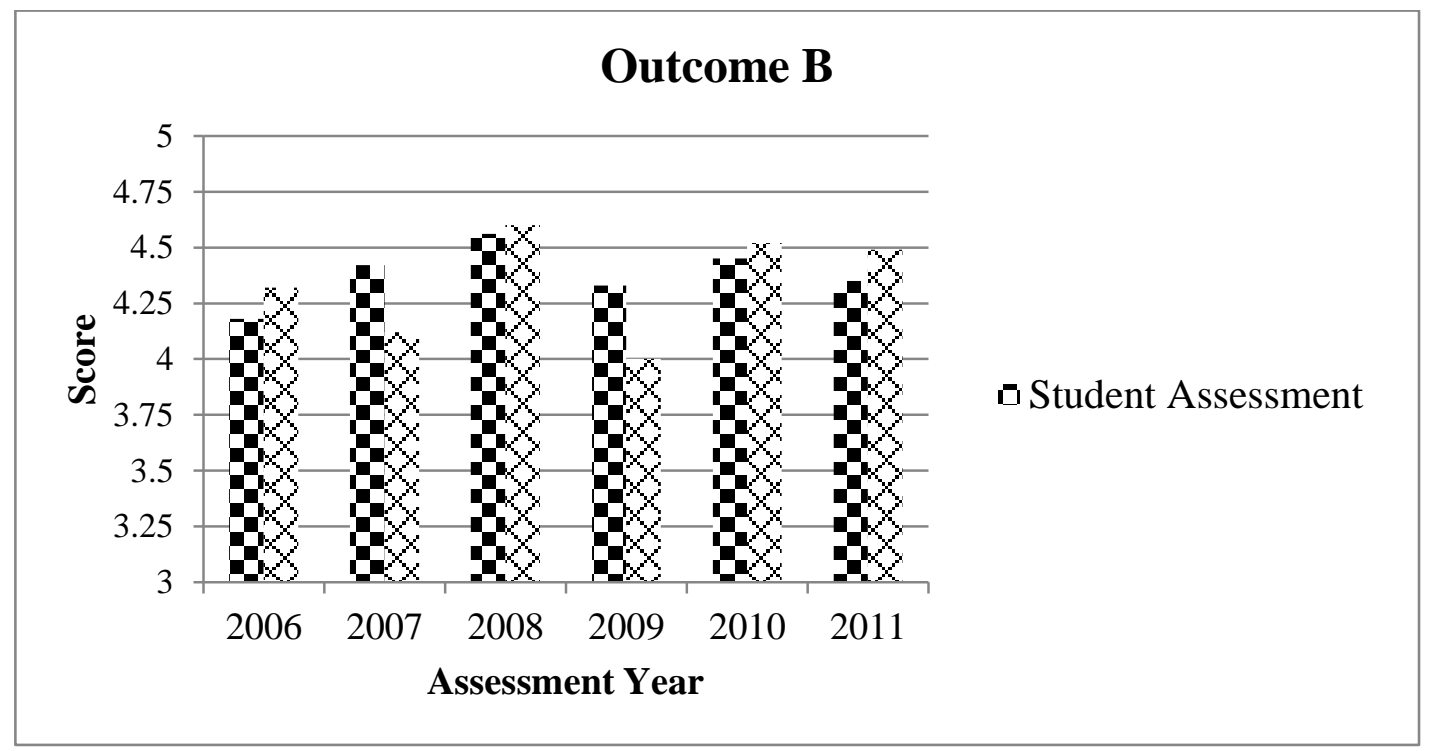

Figure 6 - Assessment of Students for ABET Outcome B 


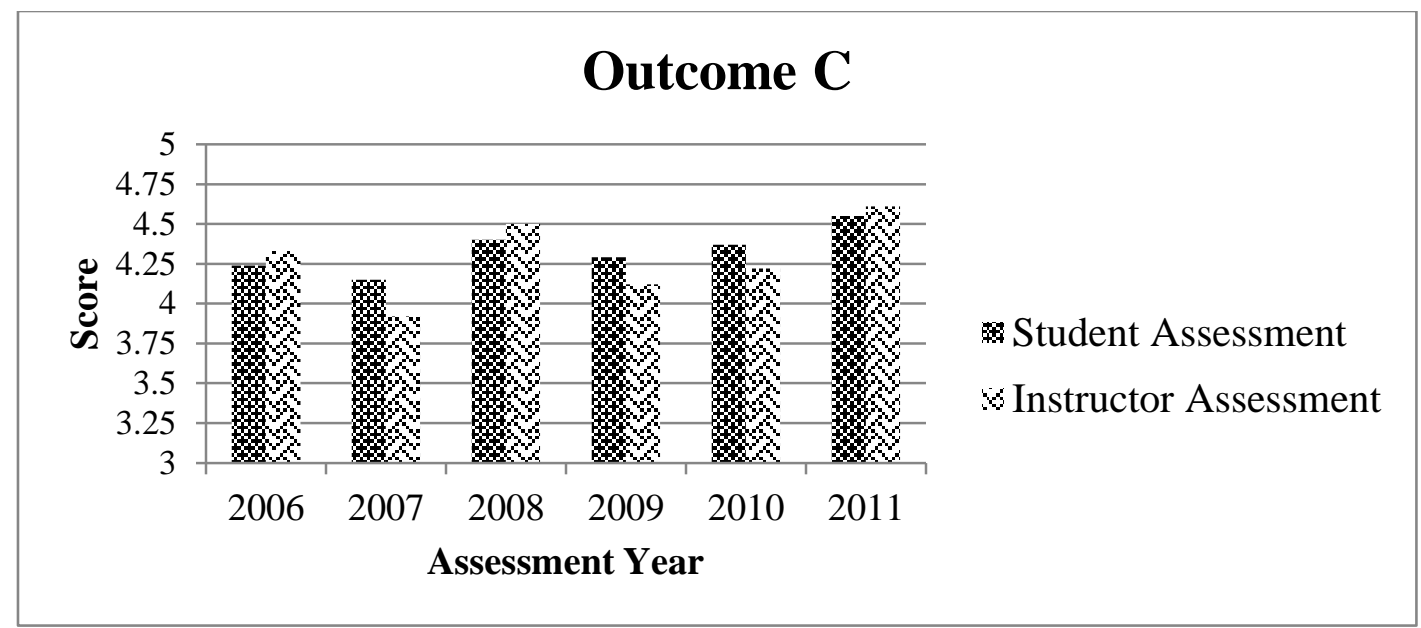

Figure 7 - Assessment of Students for ABET Outcome C

\section{Conclusions}

Product disassembly and reverse engineering can be a very useful method in teaching engineering design process. As the concept of reverse engineering is increasingly used in benchmarking, as well as improving the current design, it is very critical for engineering students to understand the procedure under study. An important element of this process, disassembling a real-world mechanical device, is practiced by students in junior engineering design process class in groups of three to four to study the behavior of the system under consideration, the physical principles behind it, and to brainstorm towards improving the current design.

Several examples of projects the students have worked on during the last several years are presented. The evidence from the students' research studies and their project reports suggests an appreciation in the learning process of engineering design. All design teams, based on one of the requirements, were engaged in the brainstorming process to improve their system under study in at least one area, whether design for function, design for manufacturing, design for assembly, material change for parts in the system, cost-effect reduction, or system performance and reliability.

Based on the studies of the products under consideration, the students design teams were able to come up with at least one design criteria from above list to improve the existing product performance. According to the students' feedback in general, these case studies appear to be a useful technique in learning of both forward and reverse engineering methods. It allows the students to have a greater insight into product conceptual design, physical principles behind it, and exploring ways to improve the current design.

The ABET outcomes for both students' and instructor's assessment prove that the reverse engineering process has been successful in our mechanical engineering program, enhancing students' skills in engineering design, hands-on experience, team-work, and engineering problem solving. This is a mock practice for our students to prepare them for challenges in their future career in the engineering industry. In addition, this type of practice helps to stimulate those students who are more creative-thinking, and motivate them to "think outside the box". 


\section{References}

[1] Eggert, R.J., “Engineering Design”, High Peak Press; 2nd edition, 2010.

[2] Jahan, K; Dusseau, R.A., "Reverse Engineering of Water Filters", Section 3551, 1999 Proceeding of the ASEE Annual Conference, June 20-23, Charlotte, North Carolina.

[3] Orta, P., et.al., "Use of Reverse Engineering as a Teaching Tools in Mechanical Engineering Education", Section 2546, 2006 ASEE Annual Conference \& Exposition, June 18-21, Chicago, Illinois.

[4] O’Brien, S; Abulencia, J.P, "Learning Through Reverse Engineering”, Section 505, 2010 ASEE Annual Conference \& Exposition, June 20 - 23, Louisville, Kentucky.

[5] Kellogg, R.S; Jenison, R., "Utilizing Reverse Engineering to Explore the Design Process", Section 2438, 1997 ASEE Annual Conference \& Exposition, June 15-18, Milwaukie, Wisconsin.

[6] McCracken, W.M; Newstetter, W., "Reverse Engineering or Design Recovery: Two Approaches to Uncovering Designing", Section 2225, 2000 ASEE Annual Conference \& Exposition, June 18-21 St. Louis, Missouri.

[7] Robertson, J; Wales, B.; Weihmeir, J., "Reverse Engineering as a Means to Design Complex Tool Design" Proceedings of the 2004 ASEE Annual Conference \& Exposition, June 20-23, Salt Lake City, Utah.

[8] Sinha, A., "Integrating a Reverse Engineering Project in a Laboratory-Based Introductory Engineering Course" Section 514, 2009 ASEE Annual Conference \& Exposition, June 1417, Austin, Texas.

[9] Otto, K.N.; Wood, K.L., “ A reverse Engineering and Redesign Methodology for Product Evolution", Proceedings of the 1996 ASME Design Engineering Technical Conferences and Design Theory and Methodology Conference, August 18-22, 1996.

[10] Student Design Project, "Reverse Engineering of a Lighted Ball-Point Pen” Junior Class of 2008-2009.

[11] Student Design Project, "Reverse Engineering of a Shop Vac ${ }^{\oplus}$ model 4025" Junior Class of 2009-2010.

[12] Student Design Project, "Reverse Engineering of an Electric Toy RC Car" Junior Class of 2010-2011.

[13] Griffiths, P.; de Hasseth, J.A. "Fourier Transform Infrared Spectrometry" Second Edition, John Wiley Publication, 2007. 